\title{
FASILITAS DAN TINGKAT OPERASIONAL PELABUHAN PERIKANAN DI KABUPATEN ACEH SELATAN PROVINSI ACEH
}

\author{
Facilities and Operational Level for Fishing Port in South Aceh District, Aceh Province \\ Oleh: \\ Kurniawan Fazri ${ }^{1}$, Iin Solihin ${ }^{2 *}$, Mustaruddin ${ }^{2}$ \\ ${ }^{1}$ Program Studi Teknologi Perikanan Laut Pascasarjana IPB, \\ Bogor, Indonesia \\ ${ }^{2}$ Departemen Pemanfaatan Sumberdaya Perikanan FPIK-IPB, \\ Bogor, Indonesia \\ *Korespondensi penulis: iin_solihin@apps.ipb.ac.id
}

\begin{abstract}
ABSTRAK
Potensi sumberdaya ikan di perairan Kabupaten Aceh Selatan yang termasuk pada Wilayah Pengelolaan Perikanan (WPP 572) relatif besar mencapai 1.240.975 ton per tahun. Namun demikian, produksi perikanan laut di wilayah ini masih relatif rendah yaitu baru mencapai 30.961,73 ton pada tahun 2020 (DKP Aceh Selatan 2020). Artinya kontribusi Kabupaten Aceh Selatan masih relatif rendah. Salah satu faktor yang diduga menyebabkan masih rendahnya pemanfaatan sumberdaya ikan di Kabupaten Aceh Selatan adalah keterbatasannya infrastruktur pelabuhan perikanan yang ada di wilayah ini. Padahal keberadaan pelabuhan perikanan ini sangat penting bagi pemanfaatan sumberdaya perikanan laut. Penelitian ini bertujuan untuk mengidentifikasi fasilitas dan tingkat operasional pelabuhan perikanan di Kabupaten Aceh Selatan. Analisis yang digunakan adalah metode komparatif yang membandingkan fasilitas dan operasional antar pelabuhan perikanan. Hasil penelitian menunjukkan bahwa ketersediaan fasilitas dasar di pelabuhan perikanan di Kabupaten Aceh Selatan rata rata baru mencapai 58,2\%. Pelabuhan perikanan dengan tingkat operasional tertinggi adalah PPI Meukek yang mencakup penyediaan bahan bakar minyak, es, air bersih, frekuensi kunjungan kapal, produksi hasil tangkapan, pedagang dan pengolah.
\end{abstract}

Kata kunci: Aceh Selatan, fasilitas, operasional, pelabuhan perikanan

\section{ABSTRACT}

The potential of fish resources in the waters of South Aceh Regency which included in the Fishery Management Area (WPP 572) is relatively large. However, marine fishery production in this region is still relatively low, reaching only 30,961.73 tons in 2020 (DKP South Aceh Regency 2020). This means that the contribution of the South Aceh Regency is relatively low. One of the factors thought to cause the low utilization of fish resources in the South Aceh Regency is the limited infrastructure of fishing ports in this region. Whereas the existence of this fishing port is very important for the utilization of marine fishery resources. This study aims to identify the facilities and operational levels of fishing ports in the South Aceh District. The analysis used is a comparative method that compares facilities and operations between fishing ports. The results showed that the availability of basic facilities at fishing ports in the South Aceh Regency on average only reached $58.2 \%$. The fishing port with the highest operational level is PPI Meukek which includes the provision of fuel oil, ice, clean water, frequency of ship visits, production of catches, traders, and processors.

Key words: facilities, fishing port, operational, South Aceh

\section{PENDAHULUAN}

Pelabuhan perikanan sangat penting perannya terhadap perikanan tangkap, karena pelabuhan perikanan merupakan pusat perekonomian mulai saat ikan didaratkan pasca penangkapan dari daerah penangkapan sampai awal ikan dipasarkan (Lubis 2011). Pelabuhan perikanan telah memberikan dampak pengganda bagi pertumbuhan ekonomi, yang pada gilirannya dapat meningkatkan kesejahteraan masyarakat (Suherman dan Dault 2009). 
Pelabuhan perikanan merupakan infrastruktur yang dibangun pemerintah dengan orientasi pelayanan kepada para pengguna pelabuhan guna memperlancar kegiatan pemasaran produk perikanan dengan harapan kesejahteraan nelayan dapat terwujud (Muninggar 2008). Aktivitas pelabuhan perikanan tidak terlepas dari proses saling mempengaruhi tidak hanya dengan masyarakat di sekitar pelabuhan namun juga dengan pelabuhan perikanan lainnya. Hal ini dominan terjadi karena adanya kesamaan jenis usaha, karakteristik aktivitas dan relasi pelaku aktivitas di pelabuhan perikanan tersebut (Putri dan Solihin 2012). Calderon dan Serven (2004) dalam Putra dan Djalante (2016) menunjukkan dalam penelitiannya bahwa adanya dampak pengembangan infrastruktur pada pertumbuhan ekonomi dan distribusi pendapatan. Tentu pelabuhan perikanan termasuk dalam konteks pengembangan infrastruktur yang akan memberikan dampak pada pertumbuhan ekonomi dan pendapatan.

Upaya mewujudkan pelabuhan perikanan yang dapat menunjang aktivitas perikanan diperlukan suatu pembangunan, pengembangan dan pengelolaan pelabuhan perikanan yang terencana. Strategi diperlukan oleh setiap pelabuhan perikanan (PP) agar memiliki arah yang jelas dalam mencapai sasaran yang diinginkan dan mengembangkan competitive advantage sehingga pelabuhan perikanan tidak hanya dapat bertahan, tetapi juga dapat memenangkan persaingan (Suherman 2011).

Aceh Selatan merupakan salah satu kabupaten yang terletak di Provinsi Aceh dimana sebagian besar merupakan wilayah pesisir. Kabupaten ini berada di pantai barat selatan Provinsi Aceh yang berhadapan langsung dengan Samudera Hindia yang termasuk pada Wilayah Pengelolaan Perikanan (WPP) 572. Potensi sumberdaya ikan yang ada di perairan ini diperkirakan mencapai 1.240. 975 per tahun dengan produksi . Namun demikian, potensi yang besar tersebut belum dimanfaatkan secara optimal. Data Dinas Kelautan dan Perikanan Kabupaten Aceh Selatan menyebutkan bahwa produksi perikanan laut kabupaten ini baru mencapai 30.961,73-ton pada tahun 2020. Artinya kontribusi Kabupaten Aceh Selatan masih relatif rendah.

Salah satu faktor yang diduga menyebabkan masih rendahnya pemanfaatan sumberdaya ikan di Kabupaten Aceh Selatan adalah keterbatasannya infrastruktur pelabuhan perikanan yang ada di wilayah ini. Padahal keberadaan pelabuhan perikanan ini sangat penting bagi pemanfaatan sumberdaya perikanan laut. Hal ini disebabkan karena keberadaan pelabuhan perikanan dapat memberikan kemudahan bagi nelayan dan para pelaku perikanan lainnya untuk beraktifitas. Sampai saat ini Kabupaten Aceh Selatan bahkan di pantai barat selatan Aceh ini belum ada pelabuhan perikanan besar. Sebagian besar pelabuhan perikanan yang ada masih terbatas pada pangkalan pendaratan ikan.

Oleh karena itu, penelitian ini bertujuan untuk mengidentifikasi fasilitas dan tingkat operasional pelabuhan perikanan di Kabupaten Aceh Selatan. Hasil penelitian ini dapat memberikan gambaran terutama kepada Pemerintah Provinsi Aceh sebagai pengelola untuk mengembangkan fasilitas dan operasional kepelabuhanannya sehingga memudahkan untuk perencanaan pengembangan selanjutnya.

\section{METODE PENELITIAN}

Penelitian ini dilakukan di lima lokasi pelabuhan perikanan yang ada di Kabupaten Aceh Selatan, Provinsi Aceh. Lokasi tersebut meliputi Pelabuhan Perikanan Pantai (PPP) Labuhan Haji (LH), Pangkalan Pendaratan Ikan (PPI) Sawang Ba'u (SB), PPI Meukek (MK), PPI Batu Lhok Paoh (BL) dan PPI Lhok Bengkoang (LB). Jenis data yang dikumpulkan terdiri dari data primer dan data skunder. Data primer diperoleh secara langsung dari lima PP yang dilakukan secara obsevasi maupun wawancara. Sedangkan data sekunder diperoleh dari literatur yang berasal dari buku pelabuhan perikanan tangkap, jurnal ilmiah, hasil penelitian, serta literatur lainya yang dapat mendukung kelengkapan data penelitian.

Pengumpulan data primer menggunakan metode purposive sampling. Menurut Sukandarrumidi (2012) metode purposive sampling adalah penentuan pengambilan sampel atas pertimbangan peneliti yang sesuai dengan maksud dan kriteria tujuan penelitian. Kriteria responden yang dipilih dalam penelitian merupakan stakeholder yang memiliki kepentingan terkait operasioanal pelabuhan perikanan baik secara langsung ataupun tidak langsung, memiliki pemahaman terkait kondisi dan operasional pelabuhan perikanan, dapat memberikan informasi yang dibutuhkan dan mampu berkomunikasi dengan baik.

Fasilitas dan operasional pelabuhan perikanan dianalisis dengan menggunakan metode komparatif yaitu dengan membandingkan kelengkapan fasilitas dan tingkat operasional pelabuhan perikanan dengan ketentuan yang berlaku. Ketentuan yang dijadikan dasar perbandingan adalah ketentuan fasilitas pelabuhan perikanan yang tercantum dalam Peraturan Menteri Kelautan dan Perikanan No. 8 tahun 2012. Peraturan tersebut menyebutkan tentang fasilitas dasar yang harus ada pada suatu Pelabuhan perikanan (pasal 4 ayat 
5) yaitu (i) fasilitas pokok terdiri dari lahan, dermaga, kolam pelabuhan, jalan komplek dan drainase; (ii) fasilitas fungsional terdiri dari kantor administrasi elabuhan, TPI, suplai air bersih, dan instalasi listrik; dan fasilitas penunjang terdiri dari pos jaga dan MCK. Penentuan tingkat ketersediaan fasilitas-fasilitas tersebut didasarkan pada Tabel 1.

Tabel 1 Penilaian tingkat ketersediaan fasilitas pelabuhan perikanan

\begin{tabular}{ll}
\hline Tingkat ketersediaan fasilitas (\%) & Kesimpulan \\
\hline $0-25$ & Sangat kurang memadai \\
$26-50$ & Kurang memadai \\
$51-75$ & Memadai \\
$76-100$ & Sangat memadai \\
\hline
\end{tabular}

Sedangkan aktifitas operasional mencakup aktifitas perbekalan melaut, kedatangan kapal dan pemasaran/distribusi hasil tangkapan. Analisa tingkat operasional ini dilihat dari besaran operasional pelabuhan perikanan tersebut. Pengambilan kesimpulan dari aspek operasional ini didasarkan pada kondisi operasional terendah sampai tertinggi, dan kemudian diberikan nilai 1 untuk operasional terendah sampai 5 untuk operasional tertinggi dan 2, 3 dan 4 diantara kedua nilai tersebut.

\section{HASIL DAN PEMBAHASAN}

\section{Fasilitas Pelabuhan Perikanan}

Pelabuhan perikanan merupakan infrastruktur perikanan dan bagian dari sistem perikanan tangkap yang berperan sebagai instansi untuk memberikan pelayanan terbaik dalam pemenuhan kepentingan masyarakat perikanan, terutama nelayan sebagai salah satu elemen yang memiliki peran dominan dalam menggerakan kegiatan perikanan (Nurhayatin et al. 2016). Keberhasilan operasional pelabuhan perikanan tidak terlepas dari faktor infrastruktur pendukung yang ada, salah satunya adalah tersedianya fasilitas di pelabuhan perikanan (Najah et al. 2012). Ketidakcukupan kapasitas atau ketersediaan salah satu fasilitas yang diperlukan akan dapat menghambat kelancaran aktivitas pelabuhan tersebut (Lubis dan Mardiana 2011).

PERMEN KP No. 08 Tahun 2012 tentang Kepelabuhan Perikanan menyatakan bahwa setiap pelabuhan perikanan memiliki fasilitas yang terdiri dari fasilitas pokok, fungsional dan penunjang. Berdasarkan aturan tersebut, terdapat 11 fasilitas dasar yang harus ada di suatu pelabuhan perikanan. Kelima pelabuhan perikanan di Kabupaten Aceh Selatan ini belum sepenuhnya dilengkapi dengan fasilitas yang memadai. PPP Labuhan Haji (LH) merupakan pelabuhan perikanan dengan fasilitas dasar yang paling lengkap yaitu 91\% dari kebutuhan fasilitas dasar dan yang paling sedikit adalah PPI Sawang Ba'u yang hanya $27 \%$. Fasilitas dasar yang tidak ada di semua pelabuhan perikanan adalah pos jaga, dermaga dan kantor administrasi pelabuhan perikanan sebagaimana disajikan pada Tabel 2.

Meskipun ketersediaan fasilitas dasar belum dipenuhi secara menyeluruh, namun pelabuhan pelabuhan perikanan di Kabupaten Aceh Selatan ini telah dilengkapi dengan berbagai fasilitas fungsional (Tabel 3). Terdapat empat fasilitas yang dimiliki oleh semua pelabuhan perikanan yaitu breakwater, turap, kolam pelabuhan dan tempat ibadah. Hal ini diduga karena tiga fasilitas tersebut sangat diperlukan bagi operasional pelabuhan perikanan dan fasilitas keempat terkait dengan aspek spiritual masyarakat setempat yang memang dikenal relijius.

Ketersediaan fasilitas di pelabuhan perikanan berfungsi untuk memperlancar aktivitas di suatu pelabuhan perikanan. Namun, dari lima pelabuhan perikanan masih minim dengan ketersediaan fasilitas baik fasilitas pokok, fungsional dan penunjang. Ketersediaan fasilitas pokok yang relatif lengkap (ada di setiap pelabuhan) adalah penahan gelombang (breakwater), turap (revetment), kolam pelabuhan, dan lahan. Sedangkan fasilitas pokok lainnya hanya terdapat di beberapa pelabuhan. Misalnya dermaga hanya terdapat di PPP Labuhan Haji dan PPI PPI Lhok Bengkoang. Padahal keberadaan fasilitas dermaga sangat penting untuk merapat dan menambatkan kapal yang melakukan bongkar dan muat barang (Tehupuring et al. 2019). Dalam konteks pelabuhan perikanan, dermaga berfungsi untuk membongkar dan memuat hasil tangkapan. Ketiadaan dermaga di Pelabuhan perikanan dapat berimplikasi berkurangnya kunjungan kapal ke Pelabuhan perikanan tersebut. Fasilitas pokok lain adalah drainase yang hanya ada di PPP Labuhan Haji. Drainase ini penting untuk membuang air di permukaan tanah yang berlebihan atau menurunkan atau menjaga muka air tanah agar tidak menjadi genangan (Suhardjono 1984 dalam Rachmawati 2010). Semua 
fasilitas pokok yang ada di pelabuhan perikanan tersebut berfungsi dengan baik sesuai dengan peruntukannya.

Tabel 2 Keberadaan fasilitas dasar pelabuhan perikanan

\begin{tabular}{|c|c|c|c|c|c|c|}
\hline \multirow[t]{2}{*}{ No } & \multirow[t]{2}{*}{ Jenis Fasilitas } & \multicolumn{5}{|c|}{ pelabuhan perikanan } \\
\hline & & $\mathrm{LH}$ & MK & SB & LP & LB \\
\hline \multicolumn{7}{|c|}{ Fasilitas Pokok } \\
\hline 1 & Lahan & 1 & 1 & 1 & 1 & 1 \\
\hline 2 & Dermaga & 1 & - & - & - & 1 \\
\hline 3 & Kolam Pelabuhan & 1 & 1 & 1 & 1 & 1 \\
\hline 4 & Jalan komplek & 1 & 1 & - & 1 & 1 \\
\hline 5 & Drainase & 1 & - & - & - & - \\
\hline \multicolumn{7}{|c|}{ Fasilitas Fungsional } \\
\hline 6 & Kantor Administrasi & 1 & - & - & - & 1 \\
\hline 7 & TPI & 1 & 1 & 1 & 1 & 1 \\
\hline 8 & Suplai air bersih & 1 & 1 & - & 1 & 1 \\
\hline 9 & Instalasi listrik & 1 & - & - & - & 1 \\
\hline \multicolumn{7}{|c|}{ Fasilitas Penunjang } \\
\hline 10 & Pos Jaga & - & - & - & - & - \\
\hline 11 & MCK & 1 & 1 & - & - & 1 \\
\hline Ting & at Ketersediaan $(\%)$ & 91 & 55 & 27 & 45 & 82 \\
\hline Rata & ata ketersediaan $(\%)$ & & & & & \\
\hline
\end{tabular}

Keterangan: LH: PPP Labuan Haji; MK: PPI Meukek; SB: PPI Sawang Ba’u; LP: PPI Lhok Bengkoang; LB: PPI Batu Lhok Paoh

$$
\text { 1: ada } \quad-\text { : tidak ada }
$$

Fasilitas fungsional yang ada di semua pelabuhan perikanan hanya ada satu jenis yaitu tempat pemasaran ikan (TPI). Sedangkan fasilitas fungsional yang ada di 80\% pelabuhan perikanan ada empat jenis fasilitas yaitu instalasi air bersih, BBM, docking/slipway dan bengkel. Sedangkan fasilitas lainnya bervariasi antar pelabuhan perikanan. Bervariasinya fasilitas tersebut diduga disebabkan karena bervariasinya kebutuhan terhadap fasilitas tersebut. Fasilitas fungsional yang ada berfungsi dengan baik kecuali Tempat Pemasaran Ikan (TPI), instalasi air bersih dan pabrik es. Kondisi fasilitas tersebut kurang berfungsi dan bahkan ada beberapa dalam keadaan rusak. Fasilitas TPI kurang berfungsi disebabkan letak dan aktivitas pemasaran tidak dilakukan secara langsung di pelabuhan perikanan sehingga TPI digunakan oleh nelayan sebagai tempat perbaikan jaring.

Fasilitas penunjang terdiri dari balai nelayan, wisma nelayan, tempat peribadatan, MCK, pertokoan dan pos jaga. Fasilitas fungsional ini berfungsi dengan baik kecuali MCK yang dalam keadaan rusak dan kurang berfungsi. Penyebab fasilitas tersebut kurang berfungsi diduga disebabkan karena ketersediaan air bersih yang terbatas dan juga tidak adanya pemeliharaan dari pengelola pelabuhan.

Berdasarkan pada kondisi dan ketersediaan fasilitas tersebut, maka perlu ada upaya dari pemerintah setempat untuk melengkapi dan merevitalisasi fasilitas pelabuhan perikanan yang ada. Suherman dan Dault (2009) berpendapat bahwa pengembangan pelabuhan perikanan memberikan banyak kemudahan dan keamanan bagi kapal ikan yang akan memanfaatkan berbagai fasilitas di pelabuhan, salah satunya adalah tempat tambat labuh. Fungsi dasar dari fasilitas pelabuhan tersebut adalah untuk memberikan perlindungan pada tingkat yang berbeda untuk kapal, memungkinkan transfer barang dari satu alat transportasi ke yang lain. Pelabuhan juga berfungsi sebagai simpul penghubung antara laut dan darat dan merupakan contoh nyata dari intermodalitas (Tarantola, 2005 dalam Roa et al. 2013). Dampak lanjutan dengan adanya ketersediaan dan berfungsi fasilitas ini akan merangsang aktifitas ekonomi sebagaimana fungsi pelabuhan yang merupakan suatu unit ekonomi yang berperan merangsang pertumbuhan dan perkembangan perdagangan atau perekonomian yang terdiri atas kegiatan penyimpanan, distribusi, pemrosesan, pemasaran dan lain-lain (Nasution 1996 dalam Sari 2020). Pembangunan fasilitas pelabuhan perikanan ini memerlukan kondisi khusus. Kelayakan aspek darat dan perairan merupakan syarat utama untuk membangun fasilitas pelabuhan perikanan. Salah satu pertimbangannya adalah efisiensi biaya dan efisiensi operasi penangkapan ikan (Nurani et al. 2010). 
Tabel 3 Kelengkapan fasilitas pelabuhan perikanan

\begin{tabular}{|c|c|c|c|c|c|c|c|}
\hline No & Jenis Fasilitas & LH & MK & SB & LP & LB & Kelengkapan (\%) \\
\hline \multicolumn{8}{|c|}{ Fasilitas pokok } \\
\hline 1 & Penahan Gelombang & 1 & 1 & 1 & 1 & 1 & 100 \\
\hline 2 & Turap (revetment) & 1 & 1 & 1 & 1 & 1 & 100 \\
\hline 4 & Dermaga & 1 & - & - & - & 1 & 40 \\
\hline 5 & Jetty & - & - & - & - & 1 & 20 \\
\hline 6 & Kolam pelabuhan & 1 & 1 & 1 & 1 & 1 & 100 \\
\hline 8 & Jalan kompleks & 1 & 1 & - & 1 & 1 & 80 \\
\hline 9 & Drainase & 1 & - & - & - & - & 20 \\
\hline 10 & Lahan & 1 & 1 & 1 & 1 & 1 & 100 \\
\hline \multicolumn{8}{|c|}{ Fasilitas fungsional } \\
\hline 1 & Tempat Pemasaran Ikan (TPI) & 1 & 1 & 1 & 1 & 1 & 100 \\
\hline \multirow{4}{*}{2} & Navigasi pelayaran dan komunikasi: & & & & & & \\
\hline & A. Telepon & 1 & - & - & - & - & 20 \\
\hline & B. Radio Komunikasi & 1 & - & - & - & - & 20 \\
\hline & C. Rambu-rambu & 1 & - & - & - & - & 20 \\
\hline 3 & Instalasi air bersih & 1 & 1 & - & 1 & 1 & 80 \\
\hline 4 & Instalasi pabrik es & 1 & - & - & - & 1 & 40 \\
\hline 5 & Instalasi BBM/ SPDN & 1 & 1 & - & 1 & 1 & 80 \\
\hline 6 & Instalasi listrik & 1 & - & - & - & 1 & 40 \\
\hline 7 & Dock/Slipway & 1 & 1 & 1 & - & 1 & 80 \\
\hline 9 & Bengkel & 1 & 1 & 1 & - & 1 & 80 \\
\hline 12 & Kantor administrasi PP & 1 & - & - & - & 1 & 40 \\
\hline 18 & Pagar kawasan & 1 & - & - & - & - & 20 \\
\hline \multicolumn{8}{|c|}{ Fasilitas penunjang } \\
\hline 1 & Balai pertemuan nelayan & 1 & - & - & - & 1 & 40 \\
\hline 3 & Wisma nelayan & - & & & & 1 & 20 \\
\hline 4 & Tempat peribadatan & 1 & 1 & 1 & 1 & 1 & 100 \\
\hline 5 & Mandi cuci kakus (MCK) & 1 & 1 & - & - & 1 & 60 \\
\hline 6 & Pertokoan & 1 & - & - & - & 1 & 40 \\
\hline 7 & Pos jaga & - & - & - & - & 1 & 20 \\
\hline \multicolumn{2}{|c|}{ Jumlah fasilitas } & 23 & 12 & 8 & 9 & 20 & \\
\hline
\end{tabular}

Keterangan: 1: ada $\quad$-: tidak ada

\section{Tingkat Operasional}

Operasional pelabuhan perikanan pada penelitian ini dikelompokkan kedalam tiga jenis kegiatan yaitu perbekalan melaut, frekuensi kedatangan kapal dan produksi hasil tangkapan dan pemasaran dan pengolahan hasil tangkapan. Perbekalan melaut adalah kebutuhan yang harus dipenuhi oleh nelayan untuk melancarkan kegiatan operasionalnya seperti kebutuhan BBM, es, air bersih, kebutuhan beras, minyak pelumas dan lain sebagainya. Kebutuhan perbekalan pada penelitian ini akan terfokus pada kebutuhan dan ketersedian BBM, es dan air bersih. Ketersedian dan ketercukupan perbekalan merupakan salah satu faktor yang dapat mempengaruhi efektivitas dan efisiensi aktivitas operasional penangkapan ikan. Adapun kebutuhan perbekalan melaut dari lima pelabuhan perikanan (PP) disajikan pada Tabel 4. 
Tabel 4 Perbekalan melaut untuk operasi penangkapan ikan per bulan

\begin{tabular}{|c|c|c|c|c|c|c|c|}
\hline \multirow[t]{2}{*}{ No } & \multirow{2}{*}{$\begin{array}{c}\text { Jenis Perbekalan } \\
\text { Melaut }\end{array}$} & \multicolumn{5}{|c|}{ Pelabuhan perikanan } & \multirow[b]{2}{*}{ Total } \\
\hline & & LH & MK & SB & LP & LB & \\
\hline 1. & BBM (liter) & 57.720 & 100.080 & 41.580 & 48.420 & 96.060 & 343.860 \\
\hline 2. & Es (batang) & 2.800 & 5.160 & 5.800 & 3.280 & 3.760 & 20.800 \\
\hline 3. & Air Bersih (liter) & 26.040 & 65.160 & 140.080 & 72.580 & 35.940 & 339.800 \\
\hline
\end{tabular}

Aktivitas perbekalan merupakan upaya pemenuhan kebutuhan nelayan selama melaut. Ketersedian dan ketercukupan perbekalan dapat mempengaruhi efektivitas dan efisiensi dari operasional penangkapan ikan yang berimplikasi pada peningkatan produktifitas nelayan dalam menangkap ikan.

Kebutuhan utama perbekalan nelayan adalah kebutuhan bahan bakar. Bahan bakar minyak yang digunakan oleh nelayan yakni solar. Biaya penggunaan BBM pada usaha perikanan mencapai $70 \%$ dari biaya operasional melaut (Suryawati dan Apriliani 2015). Kebutuhan BBM di lokasi studi dipenuhi oleh empat SPDN yakni, SPDN Lhok Bengkuang, SPDN Lhok Pawoh, SPDN Meukek dan SPDN PPP Labuhan Haji. SPDN menyediakan BBM bagi kapal dengan ukuran kurang dari 30 GT dimana pembeliannya diatur oleh Dinas Kelautan dan Perikanan Kabupaten Aceh Selatan. Nelayan yang membeli BBM bersubsidi yang disediakan SPDN tersebut harus mengurus surat rekomendasi yang dikeluarkan oleh DKP terlebih dahulu. Masa berlaku surat rekomendasi terhitung per 10 hari. Kuota pembelian BBM dibatasi sesuai dengan kebutuhan per trip penangkapannya.

Kebutuhan BBM paling banyak adalah PPI Meukek yaitu 100.080 liter/bulan dan yang paling sedikit adalah PPI Sawang Ba'u sebanyak 41.580 liter/bulan. Kebutuhan rata-rata BBM kapal motor kurang dari 10 GT berkisar antara 210-330 liter/trip, kapal motor 11 sampai 20 GT berkisar antara 660-990 liter/trip dan kapal motor 21 sampai 30 GT berkisar antara 1.050-1.350 liter/trip. Perbedaan kebutuhan BBM ini dipengaruhi oleh lama trip penangkapannya. Namun demikian, kebutuhan BBM belum diimbangi oleh pasokan BBM di SPDN. Kuota masing-masing SPDN perbulannya yakni SPDN Lhok Bengkuang (50 ton), SPDN Lhok Pawoh (80 ton), SPDN Meukek (90 ton) dan PPP Labuhan Haji (80 ton). Kuota BBM yang tersedia tidak mencukupi sehingga sebagian nelayan membeli solar di SPBU. Hal ini tentu akan menambah biaya transportasi dan waktu lebih lama serta perlu pengalihan tujuan pembelian solar dari SPDN ke SPBU.

Es balok merupakan kebutuhan perbekalan yang dimanfaatkan sebagai media untuk menjaga kualitas ikan. Ketersediaan es balok di suatu pelabuhan perikanan menjadi sangat penting. Tidak hanya bagi nelayan, es juga diperlukan oleh para pedagang untuk pendistribusian ikan ke luar kabupaten. Namun, saat ini permasalahan kebutuhan es belum dapat dipenuhi oleh pasokan es yang ada sehingga nelayan membeli di luar pelabuhan perikanan dengan biaya lebih mahal dibandingkan dengan harga es yang dijual di pelabuhan perikanan. Perbedaan harga disebabkan oleh sumber ketersediaan es di pelabuhan perikanan berbeda-beda. Bila es diproduksi oleh pabrik es di pelabuhan perikanan harga jual berkisar Rp20.000,00/batang (1 batang ekuivalen $30 \mathrm{~kg}$ ). Namun bila es balok dibeli dari pabrik es luar pelabuhan harga es mencapai Rp23.000,00/batang-Rp.30.000,00/batang. Harga es curah berkisar antara Rp2.000,00Rp3.000,00/kg. Ketersediaan pabrik es di pelabuhan perikanan dapat dilihat pada Tabel 5.

Tabel 5 Ketersediaan pabrik es

\begin{tabular}{clrrr}
\hline No & Pelabuhan Perikanan & Pabrik es (unit) & Kapasitas (ton) & Kondisi operasional \\
\hline 1 & PPI Lhok Bengkuang & 1 & 10 & Aktif \\
2 & PPI Lhok Pawoh & - & - & - \\
3 & PPI Sawang Ba'u & 1 & - & Tidak aktif \\
4 & PPI Meukek & - & - & - \\
5 & PPP Labuhan Haji & 1 & 15 & Aktif \\
\hline
\end{tabular}

Sumber: DKP Aceh Selatan, 2020

Pabrik es hanya ada di tiga pelabuhan perikanan dan satu diantaranya tidak aktif. Pabrik es yang masih melakukan aktivitas produksi terdapat di PPP Labuhan Haji dengan kapasitas 15 ton dengan berat es per batang $50 \mathrm{~kg}$. Total produksi pabrik es tersebut berkisar 300 batang/hari. Sementara pabrik es yang ada di PPI Lhok bengkuang memiliki kapasitas 10 ton. Total produksi per hari 400 batang/ hari dengan berat es $30 \mathrm{~kg} /$ batang. Nelayan harus melakukan pemesanan satu atau dua hari sebelum keberangkatan ke laut. Hal ini disebabkan ketersediaan es balok di pelabuhan perikanan terbatas. Sementara pabrik es dari luar pelabuhan perikanan memerlukan waktu untuk proses pengangkutan. Kebutuhan es terbanyak terdapat di PPI Sawang Ba'u sebesar 5.800 batang/bulan dan kebutuhan es terendah terdapat di PPI Labuhan Haji 
sebesar 2.800 batang/bulan. Kebutuhan es balok dipengaruhi oleh ukuran palka dan juga lama trip. Secara umum penggunaan es balok terbanyak terjadi pada kapal pancing dan kapal pukat cincin dengan kebutuhan rata-rata mencapai 80 batang/trip.

Air bersih pada umumnya dimanfaatkan oleh nelayan untuk memenuhi kebutuhan minum selama melaut, mencuci ikan dan membersihkan fasilitas di pelabuhan perikanan. Nelayan memenuhi kebutuhan air mineral selama melaut dengan membeli dari depot isi ulang dan juga penyedia air bersih menggunakan mobil. Sementara untuk kebutuhan air bersih di pelabuhan perikanan dilakukan dengan menyediakan tandon penampungan air bersih. Nelayan di pelabuhan perikanan yang tidak memiliki ketersediaan air bersih, pemenuhan air bersihnya menggunakan air bersih milik warga (sumur bor) dan air laut dari kolam pelabuhan.

Ketersediaan air bersih masih dirasa kurang terpenuhi. Pelabuhan yang memiliki ketersediaan air bersih hanya ada di dua pelabuhan perikanan dengan kapasitas masing-masing 2.000 liter. Dua pelabuhan perikanan lainnya memiliki 1 tandon dengan kapasitas 500 liter, namun tidak berfungsi. Kebutuhan air bersih terbanyak terdapat di PPI Sawang Ba'u sebesar 140.080 liter dan paling sedikit terdapat di PPP Labuhan Haji sebesar 26.040 liter. Kebutuhan air bersih per trip nelayan dipengaruhi oleh banyaknya jumlah ABK kapal dan lama trip. Jumlah ABK kapal motor ukuran kurang dari 10 GT berjumlah 2-8 orang, ABK kapal ukuran 11-20 GT berkisar antara 14-20 orang dan ABK kapal motor ukuran diatas 30 GT berkisar antara 20-35 orang.

Pelabuhan perikanan yang tidak memiliki ketersediaan air bersih untuk kebutuhan selama melaut biasanya melakukan pemesanan air bersih di depot air. Nelayan membeli dengan harga Rp5.000/jerigen. Alat Penyimpanan air bersih (wadah) pada kapal memiliki jenis yang berbeda-beda. Ada yang menggunakan jerigen dan juga fiberglass yang diletakan di samping belakang kapal.

Tingginya aktivitas pada suatu pelabuhan perikanan salah satunya ditunjukkan dengan frekuensi kunjungan kapal ke pelabuhan perikanan tersebut. Sebagian besar nelayan melakukan kunjungan ke pelabuhan perikanan dengan tujuan mendaratkan hasil tangkapannya. Oleh karena itu, ada keterkaitan antara frekuensi kunjungan kapal dengan jumlah hasil tangkapan yang didaratkan.

Frekuensi kunjungan kapal didominasi oleh perahu tanpa motor, perahu motor dan juga kapal motor ukuran di bawah 10 GT. Frekuensi kunjungan kapal tertinggi terdapat di PPP Labuhan Haji sebanyak 31.440 kali dan frekuensi kunjungan kapal terendah terdapat di PPI Sawang Ba'u sebanyak 8.628 kali. Hasil wawancara dengan pengelola PPP Labuhan Haji menunjukkanbahwa kunjungan kapal di pelabuhan tidak hanya bersumber dari kapal yang berpangkalan di PPP Labuhan Haji tetapi berasal dari pelabuhan perikanan lain (Tabel 6).

Tabel 6 Frekuensi kedatangan kapal dan volume produksi yang didaratkan

\begin{tabular}{clrrr}
\hline \multirow{2}{*}{ No } & \multirow{2}{*}{ Pelabuhan perikanan } & \multirow{2}{*}{ Kunjungan kapal } & \multicolumn{2}{c}{ Volume produksi (ton) } \\
\cline { 4 - 5 } & PPI Lhok Bengkuang & 30.708 & $1.477,63$ & per hari \\
2 & PPI Lhok Pawoh & 11.396 & $4.157,66$ & 4,05 \\
3 & PPI Sawang Ba'u & 8.628 & $7.127,41$ & 11,39 \\
4 & PPI Meukek & 30.600 & $3.809,57$ & 19,53 \\
5 & PPP Labuhan Haji & 31.440 & $3.974,11$ & 10,44 \\
\hline
\end{tabular}

Sumber: DKP Aceh Selatan, 2020 (diolah)

Tabel 6 menunjukkan bahwa tingginya frekuensi pendaratan tidak selalu berkorelasi positif dengan jumlah hasil tangkapan yang didaratkan. Hal ini terlihat dari kenyataan bahwa PPI Sawang Ba'u dengan frekuensi kunjungan kapal yang relatif lebih rendah tetapi hasil tangkapan yang didaratkan lebih banyak dibandingkan pelabuhan lainnya. Volume produksi tertinggi terdapat di PPI Sawang Ba'u sebanyak 7.721,37 ton dan volume produksi terendah terdapat di PPI Lhok Bengkuang sebanyak 1.477,63 ton. Adapun jenis hasil tangkapan ekonomis penting yang cukup tinggi didaratkan secara umum adalah kakap merah (red snappers), kurisi (treadfin breams), layang (scads), selar (trevallies), kuwe (jack trevallies), kembung (indian mackerels), tembang (fringescale sardinella), lemuru (indian oil sardinella), tenggiri (narrow barred king mackerel), tuna, cakalang (skipjack tuna), tongkol (easterm little tuna), lemadang (common dolphin fish) dan teri (anchovies).

Aktivitas pendaratan hasil tangkapan di PPI Lhok Bengkuang, PPI Lhok Pawoh, PPI Sawang Ba'u, PPI Meukek dan PPP Labuhan Haji relatif sama dimana proses pendaratan hasil tangkapan dimulai dari 
pembongkaran ikan dari palka ke dek kapal, kemudian dilakukan penyortiran baik dari jenis, ukuran dan kondisi fisik ikan. Selanjutnya dilakukan pengangkutan ke dermaga menggunakan keranjang yang terbuat dari rotan ataupun keranjang plastik kemudian diangkut ke TPI ataupun ke gudang pengepakan menggunakan alat bantu transportasi (mobil pick up/becak).

Aktivitas pendaratan ikan dilakukan pada pagi dan sore hari. Perahu motor dan perahu tanpa motor melakukan aktivitas pendaratan ikan antara pukul 11.00 WIB dan pukul 17.00 WIB. Sementara kapal motor melakukan aktivitas pendaratan ikan dimulai pukul 06.00 WIB dan 16.00 WIB. Perbedaan waktu pendaratan ikan disebabkan perahu motor dan perahu tanpa motor melakukan aktivitas penangkapan one day fishing. Aktivitas penangkapan dilakukan mulai pukul 06.30 WIB dan kembali ke darat antara pukul 11.00 WIB. Sebagian nelayan kembali melaut setelah beristirahat dan kembali ke darat antara pukul 17.00 WIB. Berbeda dengan kapal motor dimana aktivitas penangkapan dilakukan antara 1 sampai 24 hari per trip.

Proses pendaratan ikan di pelabuhan perikanan berbeda-beda. Perahu motor dan perahu tanpa motor dapat langsung mendaratkan hasil tangkapan ke turap ataupun tepi kolam pelabuhan. Namun, kapal motor dengan ukuran diatas 10 GT tidak dapat melakukan hal tersebut disebabkan luas kolam pelabuhan tidak mencukupi dan terjadi pendangkalan. Akibatnya nelayan mendaratkan hasil tangkapan menggunakan alat bantu boat fiber.

Aktivitas pemasaran hasil tangkapan merupakan salah satu aktivitas ekonomi yang terjadi di pelabuhan perikanan. Tingginya volume produksi yang didaratkan akan mempengaruhi aktivitas ekonomi masyarakat dis ekitar pelabuhan perikanan. Lembaga pemasaran yang ada di pelabuhan perikanan terdiri dari Konsumen, pengecer, moge, pengusaha dan toke bangku.

Sistem pemasaran hasil tangkapan yang ada di lima pelabuhan perikanan tidak dilakukan melalui sistem lelang, meskipun di pelabuhan perikanan terdapat fasilitas Tempat Pemasaran Ikan (TPI). Fasilitas TPI dimanfaatkan sebagai tempat pemasaran ikan bagi pengecer dan juga tempat nelayan melakukan penimbangan hasil tangkapan sebelum dilakukan pengepakan untuk didistribusikan keluar kabupaten ataupun provinsi. Terdapat dua pelaku pemasaran lokal yang ada di pelabuhan perikanan yakni pengecer dan pedagang moge. Adapun jumlah pedagang ikan per kecamatan yang ada dapat dilihat Tabel 7.

Tabel 7 Jumlah pedagang dan pengolah ikan per kecamatan

\begin{tabular}{clrrr}
\hline No & Kecamatan & Pedagang Ikan (orang) & Pengolah ikan (Orang) \\
\hline 1 & Tapak Tuan & 91 & & 4 \\
2 & Sawang & 89 & \\
3 & Meukek & 101 & 22 \\
4 & Labuhan Haji & 65 & & 28 \\
\hline
\end{tabular}

Sumber: DKP Kabupaten Aceh Selatan 2020

Pedagang ikan tersebut terdiri dari pedagang ikan segar (moge dan pengecer) dan pedagang ikan olahan. Jumlah pedagang ikan terbanyak terdapat di Kecamatan Meukek sebanyak 101 pedagang dan paling sedikit di kecamatan Labuhan Haji sebanyak 65 pedagang. Jumlah pedagang ikan di empat kecamatan tersebut didominasi oleh pedagang pengecer dan moge. Jumlah usaha pengolah ikan terbanyak terdapat di Kecamatan Labuhan Haji sebanyak 28 orang dan terendah terdapat di Kecamatan Tapak Tuan yaitu orang. Banyaknya jumlah pedagang dan pengolah ikan tentu akan berpengaruhi besar terhadap pemanfaatan hasil tangkapan baik untuk konsumsi ataupun sebagai bahan baku olahan.

Tujuan pemasaran hasil tangkapan nelayan adalah pasar lokal dan regional. Pasar lokal adalah pemasaran hasil tangkapan ikan yang dilakukan antar kabupaten yang berada dalam satu provinsi dengan lokasi pelabuhan periakanan. Sementara pasar regional adalah tujuan pasar di luar provinsi dimana pelabuhan perikanan berada. Adapun tujuan pasar lokal yakni Nagan raya, Meulaboh, Singkil, Subussalam, Lhokseumawe, Bireun, Langsa dan Banda Aceh serta sekitar Kabupaten Aceh Selatan. Sementara tujuan pemasaran regional yakni Sumatra Utara, Sumatra Barat dan Jambi. Pemasaran hasil tangkapan tujuan lokal dan regional terdiri dari ikan segar dan juga ikan olahan. Alat transportasi yang digunakan untuk proses pendistribusian ikan menggunakan mobil pick up dan truk. Ikan yang didistribusikan dipakcing menggunakan box fiber ukuran $180 \mathrm{~kg}$ dan di beri es curah untuk menjaga mutu hasil tangkapan.

Berdasarkan penjelasan di atas dapat disampaikan bahwa pelabuhan perikanan di Kabupaten Aceh Selatan secara keseluruhan telah beroperasi. Hal ini ditunjukkan dengan berlangsungnya berbagai aktifitas 
operasional di pelabuhan perikanan. Namun demikian operasional yang paling tinggi terjadi di PPI Meukek, disusul kemudian oleh PPI Sawang Ba’u dan PPP Labuhan Haji dan (Tabel 8).

Tabel 8 Penilaian tingkat operasional pelabuhan perikanan

\begin{tabular}{llrrrrr}
\hline \multirow{2}{*}{ No } & \multicolumn{2}{c}{ Aspek operasional } & \multicolumn{5}{c}{ Pelabuhan perikanan } \\
\cline { 3 - 7 } & & LH & MK & SB & LP & LB \\
\hline 1. & BBM (liter) & 3 & 5 & 1 & 2 & 4 \\
\hline 2. & Es (batang) & 3 & 4 & 5 & 1 & 2 \\
\hline 3. & Air Bersih & 1 & 3 & 5 & 4 & 2 \\
\hline 4. & Frekuensi kunjungan & 5 & 3 & 1 & 2 & 4 \\
\hline 5. & Produksi hasil tangkapan & 3 & 2 & 5 & 4 & 1 \\
\hline 6. & Pedagang & 3 & 5 & 4 & 1,5 & 1,5 \\
\hline 7. & Pengolah & 5 & 4 & 3 & 1,5 & 1,5 \\
\hline Jumlah & nilai & 23 & 26 & 24 & 16 & 16 \\
\hline
\end{tabular}

Aktivitas operasional dapat menunjukkan kinerja dari suatu pelabuhan perikanan. Hasil penelitian Nugroho et al. 2012, menyimpulkan bahwa faktor faktor yang mempengaruhi kinerja pelabuhan perikanan (kasus PPI Dadap) adalah faktor internal dan eksternal dimana faktor internal adalah terkait dengan fasilitas, jumlah armada dan sedimentasi. Sedangkan faktor eksternal adalah dukungan aparatur desa, sumberdaya ikan dan daerah penangkapan. Hal ini relevan dengan penelitian ini terutama yang terkait dengan ketersediaan dan kondisi fasilitas. Penambahan dan revitalisasi fasilitas ini perlu dilakukan pemerintah Provinsi Aceh untuk meningkatkan operasional yang akan berdampak pada peningkatan kinerja pelabuhan perikanan.

\section{KESIMPULAN DAN SARAN}

Ketersediaan fasilitas dasar di pelabuhan perikanan di Kabupaten Aceh Selatan rata rata baru mencapai 58,2\%. Pelabuhan perikanan dengan tingkat operasional tertinggi adalah PPI Meukek yang mencakup penyediaan bahan bakar minyak, es, air bersih, frekuensi kunjungan kapal, produksi hasil tangkapan, pedagang dan pengolah.

\section{UCAPAN TERIMA KASIH}

Terima kasih yang sebesar besarnya disampaikan kepada Deputi Bidang Penguatan Riset dan Pengembangan Kementerian Riset dan Teknologi-Badan Riset dan Inovasi yang telah membiayai penelitian ini melalui Hibah Magister tahun 2021.

\section{DAFTAR PUSTAKA}

Dinas Kelautan dan Perikanan Kab. Aceh Selatan. 2020. Laporan Tahunan Kelautan dan Perikanan.

Lubis E. 2011. Kajian Peran Strategis Pelabuhan Perikanan terhadap Pengembangan Perikanan Laut. Akuatik: Jurnal Sumberdaya Perairan. 5(2): 1-7.

Lubis, E. \& Mardiana N. 2011. Peranan fasilitas PPI terhadap kelancaran aktivitas pendaratan ikan di Cituis Tangerang. Jurnal Teknologi Perikanan dan Kelautan. 2(1): 1-10.

Muninggar R. 2008. Analisis Supply Chain Dalam Aktivitas Distribusi di Pelabuhan Perikanan Nusantara Palabuhanratu (PPNP). Buletin PSP, 17(3): 350-355.

Najah RA, Lubis E, \& Muninggar R. 2012. Keberadaan Fasilitas Menurut Aktivitas Di Pelabuhan Perikanan Pantai Lampulo, Banda Aceh. Marine Fisheries: Journal of Marine Fisheries Technology and Management. 3(1): 55-70.

Nugroho T, Solihin I, \& Fathurohim. 2012. Faktor-Faktor Penentu Kinerja Pelabuhan Perikanan Pantai (PPP) Dadap di Kabupaten Indramayu. Marine Fisheries: Journal of Marine Fisheries Technology and Management. 3(1): 91-101.

Nurani T, Lubis E, Haluan J, \& Saad S. 2010. Analysis of Fishing Ports to Support the Development of Tuna Fisheries in the South Coast of Java. Indonesia Research Fisheries Journal. 16(2): 69-78. 
Nurhayatin OT, Muzakkir AK, \& Wibowo BA. 2016. Analisis Tingkat Kepuasan Nelayan terhadap Pelayanan Penyediaan Kebutuhan Melaut di PPN Prigi Kabupaten Trenggalek Jawa Timur. Journal of Fisheries Resources Utilization Management and Technology. 5(1): 19-27.

Putra AA, \& Djalante S. 2016. Pengembangan Infrastruktur Pelabuhan Dalam Mendukung Pembangunan Berkelanjutan. Jurnal Ilmiah Media Engineering. 6(1): 433-443.

Putri TE, \& Solihin I. 2012. Pola Interaksi antar Pelabuhan Perikanan di Kabupaten Sukabumi. Buletin PSP. 20(2): 347-358.

Rachmawati A. 2010. Aplikasi SIG (Sistem Informasi Geografis) untuk Evaluasi Sistem Jaringan Drainase di Sub Das Lowokwaru Kota Malang. Jurnal Rekayasa Sipil. 4(2): 111-123.

Roa I, Peña Y, Amante B, \& Goretti M. 2013. Ports: Definition and Study of Types, Sizes and Business Models. Journal of Industrial Engineering and Management. 6(4): 1055-1064.

Sari Z. 2020. Identifikasi Peran dan Strategi Pelabuhan Bebas Sabang. Rekayasa Hijau: Jurnal Teknologi Ramah Lingkungan. 4(3): 167-178.

Suherman A, \& Dault A. 2009. Dampak Sosial Ekonomi Pembangunan dan Pengembangan Pelabuhan Perikanan Nusantara (PPN) Pengambengan Jembrana Bali. Jurnal Saintek Perikanan. 2(1): 24-32.

Suherman A. 2011. Formulasi Strategi Pengembangan Pelabuhan Perikanan Nusantara Pengambengan Jembrana. Marine Fisheries: Journal of Marine Fisheries Technology and Management. 2(1): 87-99.

Sukandarrumidi. 2012. Metode Penelitian : Petunjuk Praktis untuk Peneliti Pemula. Yogyajarta (ID). Gajah Mada University Press.

Suryawati S.H, \& Apriliani T. 2015. Mekanisme Penyaluran Bahan Bakar Minyak Bersubsidi pada Usaha Perikanan Tangkap Skala Kecil. Jurnal Kebijakan Sosial Ekonomi Kelautan dan Perikanan. 5(1): $37-46$.

Tehupuring GP, Retraubun N, \& Telussa MF. 2019. Analisis Efektifitas Kinerja Dermaga Haria Kecamatan Saparua, Kabupaten Maluku Tengah. Jurnal Manumata. 5(2): 37-46. 